Brit. J. vener. Dis. (1960), 36, 36.

\title{
SURFACE MANIFESTATIONS OF REITER'S DISEASE IN THE MALE* $†$
}

\author{
BY \\ J. A. H. HANCOCK \\ From the Whitechapel Clinic, The London Hospital
}

The purpose of this paper is to record the incidence and certain aspects of the clinical features of the surface manifestations occurring in Reiter's disease.

The published figures of incidence can be criticized, in general, along one or more of the following lines: that authors fail to state the extent to which patients with more florid disease came under their observation; that some authors restrict the diagnosis of Reiter's disease to cases showing the triple syndrome; that no distinction may be made between the incidence calculated from one attack in each of the patients and that derived from a total of their attacks; that few authors record the quality and consistency of the physical examination; and, lastly, in the earlier literature, that keratoderma is frequently equated only with gonococcal arthritis.

\section{Case Material}

The case material of the Whitechapel Clinic suffers from biased selection in that some severely affected patients were referred for forms of treatment not at the time available elsewhere; others were diagnosed in ophthalmological departments, and some were referred from other hospitals because genital infection had been sought and the diagnosis of Reiter's disease made, only after lesions of the eyes and skin had developed in cases diagnosed as, for example, "atypical rheumatoid arthritis". In choosing the material for this series, these and similar cases have been eliminated and, of those remaining available for this study, the majority were suffering from a first attack of Reiter's disease which had developed while the patient was already attend-

* This work was carried out under the aegis of the Medical Research Council Working Party on Non-Specific Urethritis, with the aid of a grant from the United States Public Health Service.

+ Paper read at the M.S.S.V.D.-I.U.V.D.T. meeting in London. October 16, 1959. ing the clinic with a recently acquired genital infection. In the minority, in which a second or subsequent attack was the one recorded, similar precautions were taken to avoid biased selection. All the patients in this series have had the normal routine physical examination performed at their first attendance, followed by one or more special re-examinations directed to obtaining a uniform recording of the features of their attacks of Reiter's disease. This examination, together with a group of special investigations, was planned by Dr. J. K. Oates and has been continued by his successors in the department.

76 cases were available for study, and the age distribution at the time of the first recorded attack is shown in Fig. 1.

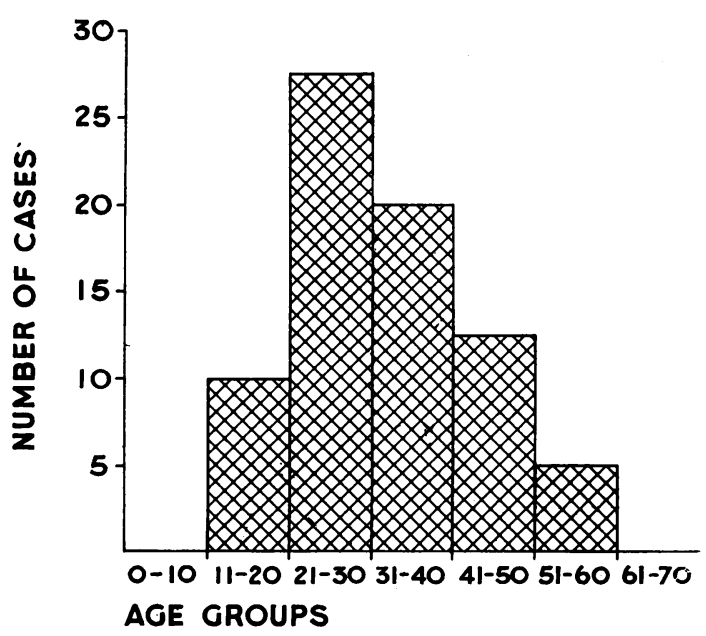




\section{Signs and Symptoms}

Fig. 2 shows the incidence of the more frequent manifestations of the disease. The incidence of arthritis ( $97 \cdot 3$ per cent.) is accounted for by the inclusion of two patients suffering from nongonococcal urethritis, conjunctivitis, typical buccal lesions, and keratoderma blennorrhagica, neither of whom developed arthritis in their first attack.

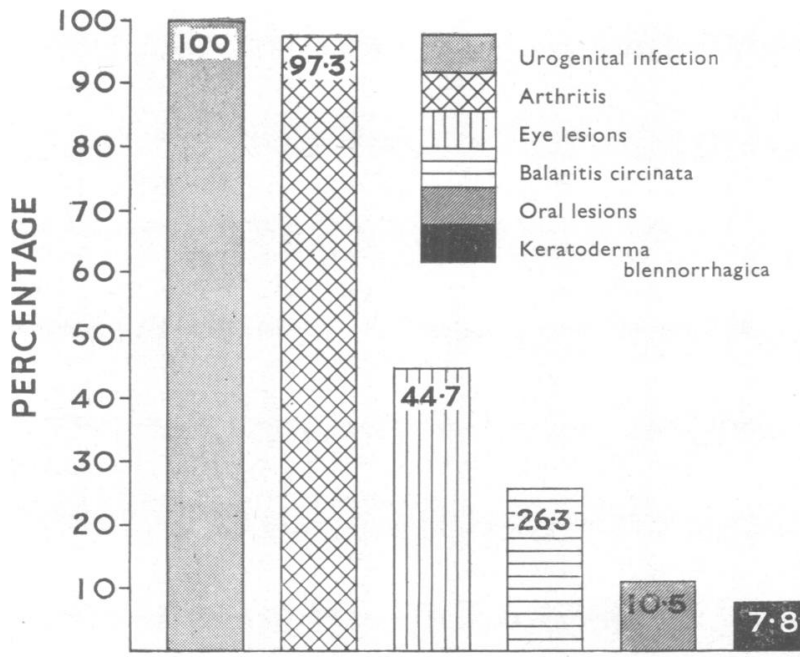

Eye Lesions.-Involvement of the eye occurred in 45 per cent. of the patients.

Conjunctivitis was seen in 37 per cent. The characteristics of the conjunctivitis did not differ from those described by other workers. It was observed that, in seven of the 34 cases the inflammation was confined to the tarsal conjunctiva at the lateral angle where it presented a somewhat distinctive, purplish, velvety appearance.

Anterior uveitis occurred in 8 per cent. of patients (Fig. 3). Two features of incidence are noted: first, that in a small number of patients, recurrences of anterior uveitis in the absence of other manifestations of Reiter's disease, may occur very frequently, some patients having as many as twenty or thirty attacks: secondly, as a result of this, if eye involvement is calculated in relation to the total of the attacks suffered by these 76 patients, anterior uveitis displaces conjunctivitis as the most frequent complication, and the total incidence of eye involvement increases by nearly 20 per cent. The inclusion of only 5 per cent. of such patients in a series in which eye involvement is calculated on an attack basis, will give a picture which is quite unrepresentative of the series as a whole.

Corneal ulceration and keratitis were not observed in this series.

FIG. 2.-Incidence of the principal manifestations of Reiter's disease.

\section{ALL ATTACKS}

76 PATIENTS HAD 173 ATTACKS OF REITER'S DISEASE

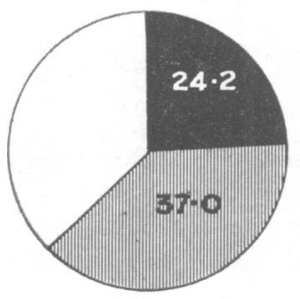

ONE OBSERVED ATTACK

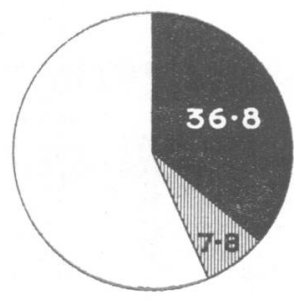


Lesions of the Buccal Cavity. -10 per cent. of patients showed lesions of the buccal cavity. The sites most frequently involved were the palate and uvula, the tongue, the mucosa of the cheeks, and the mucosa of the lips, in that order. In general, the lesions are remarkable for their painlessness and their superficial nature.

Tongue.-Lesions usually take the form of oval areas of reddened papillae, particularly prominent when the tongue is furred (Fig. 4, opposite); these may progress to superficial erosion of the papillae, producing an appearance which, at a casual glance, imitates that of so-called "geographical tongue". On rare occasions the lesion may present as a discrete, painless, shallow ulcer, 2 or $3 \mathrm{~mm}$. across, with a clean base and a smooth edge (Fig. 5, opposite), clearly distinguishable from the painful, ragged, sloughy ulcer of aphthous stomatitis.

Other Buccal Lesions.-Elsewhere in the buccal cavity three varieties of lesions are seen:

(i) A small opaque vesicle with a wide zone of surrounding erythema which breaks down to form a millet-sized, painless, shallow, clean erosion.

(ii) An area of glistening erythema, showing a granular surface when wiped dry, which progresses to become a shallow erosion with a circinate border (Fig. 6, opposite) and may later become covered with heapedup white epithelium (Fig. 7, opposite).

(iii) We have observed a confluent erythema of the soft palate. uvula, and tonsillar region, with a sharply defined anterior margin (Fig. 8, opposite).

In most cases, all types of lesions are short-lived, and not infrequently they are completely symptomless. Severe and painful stomatitis occurred in one of our cases.

Lesions of the Skin.-Keratoderma blennorrhagica occurred in 7.8 per cent. of the 76 patients. In the description of the clinical behaviour which follows, use is made of the whole of the clinic material and the records of sixteen patients who together suffered nineteen attacks are available. The distribution of the lesions during these attacks is shown in Table $I$. This is in general agreement with the findings of other workers, and confirms that the soles of the feet are almost invariably affected.
There is usually a striking symmetry in the distribution of the eruption. The initial lesion is either a discrete brownish-red maculo-papule, or a so-called "pustule", which contains brown cheesy material composed of degenerated nucleated epidermal cells accompanied by a few leucocytes. As it increases in size it becomes surmounted by a rapidly thickening scale. No bleeding points are seen when the scale is removed, and the tâche de bougie cannot be elicited. The lesion may thereafter progress to form a grotesque limpet-like accumulation of layers of scale measuring up to half an inch in thickness. In moist areas subject to friction, the scale does not become established and the lesion develops as a greasy brown maculo-papule of circinate outline which may become macerated and secondarily infected. On the weight-bearing area of the soles of the feet, and less commonly on the palms of the hands, the initial lesion is a brown macule developing to a firm vesicle, the contents of which rapidly become "pustular" (Fig. 9). Such a lesion may progress to become a thick-walled flaccid bulla covering more than a quarter of the surface of the sole of the foot. The epidermis forming the roof remains unchanged on the surface. Less commonly, the palms and soles may be affected by a diffuse hyperkeratosis without distinctive features.

Lesions of the scalp resemble psoriasis.

TABLE I

SITES OF NINETEEN ATTACKS OF KERATODERMA BLENNORRHAGICA IN SIXTEEN PATIENTS

\begin{tabular}{|c|c|c|c|c|c|c|}
\hline \multicolumn{6}{|c|}{ Site } & No. of Cases \\
\hline $\begin{array}{l}\text { Soles of feet } \\
\text { Palms and f } \\
\text { Legs (extens } \\
\text { Arms . } \\
\text { Trunk . } \\
\text { Scalp . . } \\
\text { Finger nails } \\
\text { Toe nails }\end{array}$ & $\begin{array}{l}\text { and } \\
\text { nge } \\
\text { o s } \\
\ldots \\
\ldots \\
\ldots \\
\ldots \\
\text {. }\end{array}$ & $\begin{array}{l}\text { es } \\
\cdots \\
\ldots \\
\ldots \\
\ldots \\
\ldots\end{array}$ & $\begin{array}{l}\ldots \\
\ldots \\
\cdots \\
\cdots \\
\cdots \\
\cdots\end{array}$ & $\begin{array}{l}\cdots \\
\cdots \\
\cdots \\
\cdots \\
\cdots \\
\cdots\end{array}$ & $\begin{array}{l}\cdots \\
\cdots \\
\cdots \\
\cdots \\
\cdots \\
\cdots\end{array}$ & $\begin{array}{r}18 \\
6 \\
6 \\
5 \\
5 \\
5 \\
4 \\
2 \\
1\end{array}$ \\
\hline
\end{tabular}

Exfoliative dermatitis occurred in one patient.

Involvement of the nails occurs. In the mild case, the nail plate becomes opaque, thickened, ridged, and brittle. In the more severe case, a subungual "pustule" develops and a thickening layer of friable corneous material forces the nail away from the bed and may finally cause its complete separation (Fig. 10). The rash may become generalized, and we have records of one patient who in the course of such an attack developed generalized lymphadenopathy followed by exfoliative dermatitis. When the condition ceases to be active, the lesions separate to 


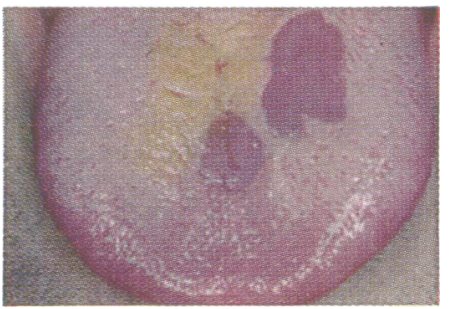

FIG. 4

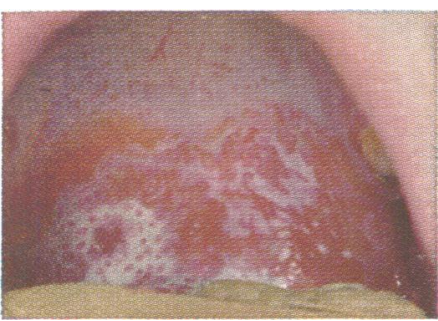

FIG. 7

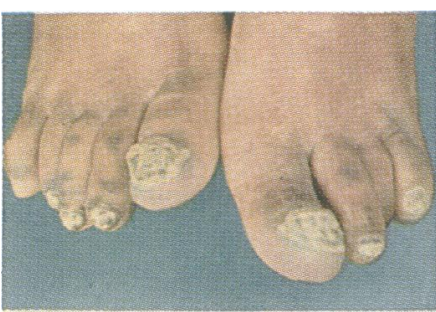

FIG. 10

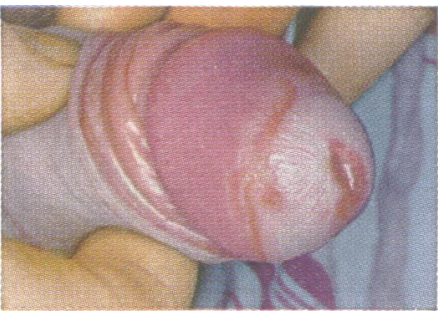

FIG. 13

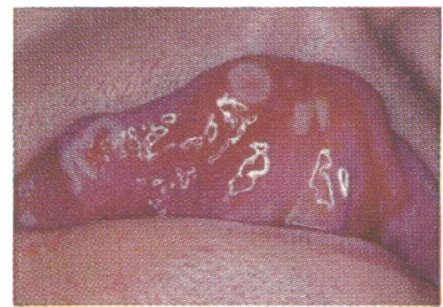

FIG. 5

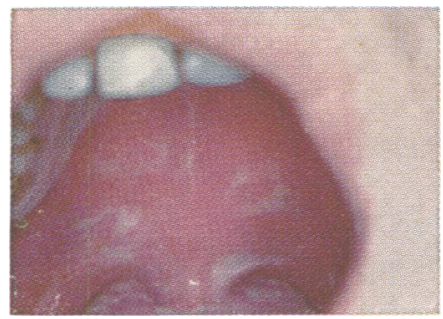

FIG. 8

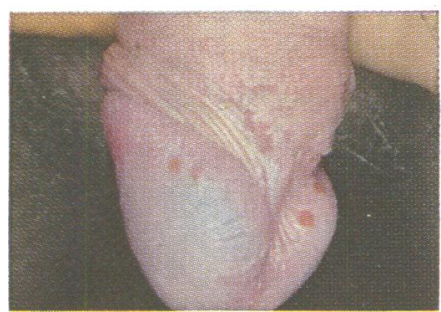

Fig. 11

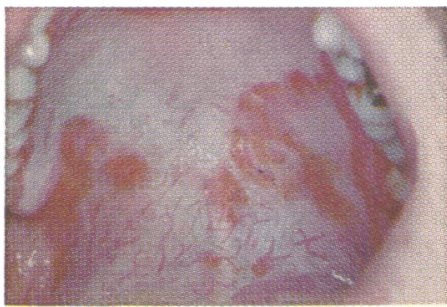

FIG. 6

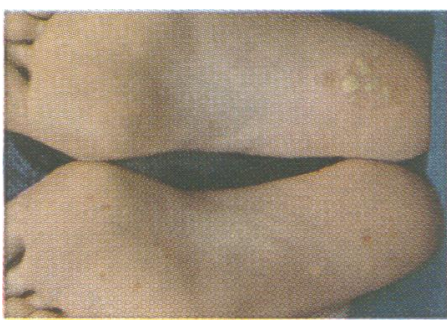

FIG. 9

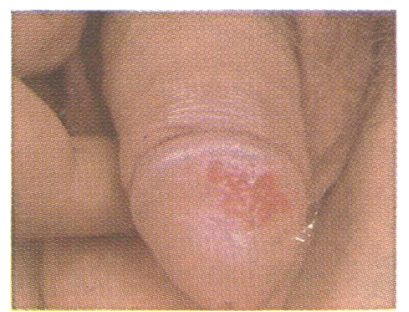

FiG. 12

FIGs. 4 and 5.-The tongue.

FIGs. 6-8.-The palate.

Figs. 9 and 10.-The feet

FIGS. 11-13.-The penis. 
reveal pink unscarred epithelium. Attacks vary considerably in their duration. We have accurate records of duration in thirteen attacks (Table II).

TABLE II

DURATION OF ATTACKS OF KERATODERMA BLENNORRHAGICA

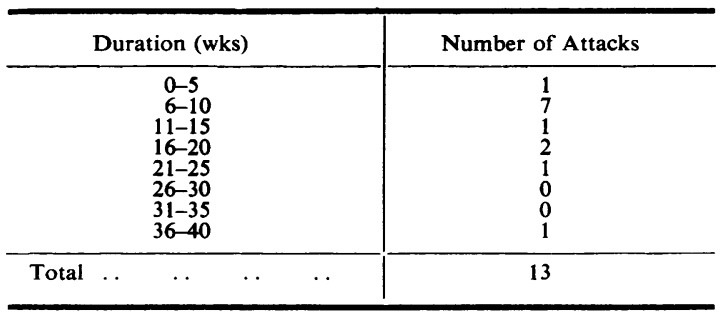

The occurrence of the Koebner phenomenon is recognized. Haase (1916) produced it by scarification, Taylor (1939) observed it in his patients' scratch marks, and Epstein and Chambers (1937) reported the development of lesions at the sites of recent burns. This same phenomenon was probably responsible for the lesions which developed when Lees and Percival (1931) injected filtrates of organisms cultured from the urethra. We have observed this phenomenon in one patient who developed lesions at the sites of cutaneous abscesses, and in another who developed a plaque of keratoderma exactly beneath his wristwatch.

Lesions of the Penis.-Lesions of keratoderma occurring on the penis differ clinically from those elsewhere on the skin only by virtue of the effects of the prepuce. They are by tradition referred to as circinate balanitis. Penile lesions occurred in 26 per cent. of the 76 patients. The early lesion may occasionally be seen as a discrete opaque vesicle, 2 to $3 \mathrm{~mm}$. across, with little or no surrounding erythema (Fig. 11). In a few hours it breaks down to form a shallow, moist, pink erosion with a slightly raised edge which assumes a circinate outline as adjacent lesions coalesce (Fig. 12). In the circumcised patient, the mature lesion becomes surmounted by a keratodermic crust, but in the uncircumcised, scale-formation does not occur beneath the prepuce and secondary infection frequently occurs with the result that the pathognomonic appearance is lost. In some cases erosions are not seen and lesions take the form of discrete papules, or areas of diffuse erythema with circinate borders (Fig. 13). The perimeatal region and the coronal sulcus are the areas most commonly affected.

Other Skin Lesions.-Psoriasis, erythema multiforme, erythema nodosum, urticaria, seborrhoeic eczema, and purpura were noted to have occurred in some of our cases. There was no reason, however, for believing that these eruptions were specifically associated with Reiter's disease.

\section{Summary}

The incidence of the surface manifestations occurring in Reiter's disease has been calculated in a series of 76 patients chosen to exclude the effects of biased selection. Eye involvement occurred in 45 per cent of patients, balanitis circinata in 26 per cent., lesions of the buccal cavity in 10 per cent, and keratoderma blennorrhagica in 7.8 per cent. Certain clinical features are described in detail.

\section{REFERENCES}

Epstein, E., and Chambers, S. O. (1937). Arch. Derm. Syph. (Chicago) 36, 1044.

Haase, M. (1916). J. cutan. Dis., 34, 817

Lees, D., and Percival, G. H. (1931). Lancet, 2, 1116.

Taylor, N. S. (1939). Brit. J. Derm., 51, 418.

\section{Manifestations superficielles de la maladie de Reiter chez le mâle}

\section{Résumé}

La fréquence des manifestations superficielles survenant dans la maladie de Reiter a été calculée dans une série de 76 malades choisis de manière à éliminer les facteurs statistiquement tendenciels. Des complications oculaires survinrent chez $45 \%$, balanitis circinata chez $26 \%$, lésions de la muqueuse buccale chez $10 \%$, et kératodermie blennorragique chez $\mathbf{7 , 8} \%$ des malades. On décrit en détail certains caractères cliniques. 